\title{
THE MODEL OF A TEMPORARY TEMPERATURE FIELD DURING MULTI-PASS ARC WELD SURFACING. PART II: EXAMPLE OF COMPUTATIONS
}

\author{
Jerzy Winczek ${ }^{1}$, Grażyna Rygat ${ }^{2}$, Tomasz Skrzypczak ${ }^{1}$ \\ ${ }^{I}$ Faculty of Mechanical Engineering and Computer Science, Czestochowa University of Technology \\ Czestochowa, Poland \\ ${ }^{2}$ Pedagogical Faculty, Jan Dlugosz University in Czestochowa, Poland \\ winczek@gmail.com,g.rygal@ajd.czest.pl,skrzyp@imipkm.pcz.czest.pl
}

\begin{abstract}
In this work computations of a temperature field are carried out during multipass Gas Metal Arc Weld surfacing of a cuboidal steel element taking into account heat of the melted electrode material. The results are presented in the form of temporary and maximum temperature distribution in the element's cross-section and thermal cycles at selected points.
\end{abstract}

Keywords: temperature field, gas metal arc weld surfacing, modelling

\section{Introduction}

The basis for welding processes is the usage of a concentrated moving heat source, which causes temperature field changeable in time and space. In the modeling of a temperature field of welding processes, its single-distributed heat source model is generally assumed, reflecting the direct impact of the electric arc on the surfaced object. The shape of the fusion lines during arc weld surfacing exhibits shape irregularity that is difficult to restore by means of the description of the temperature field obtained by using analytical method and the single-distributed heat source model. The necessity of the adoption of a bimodal heat source model in the analytical description of the temperature field is therefore essential, which was presented in [1]. In modelling of the temperature field during multi-pass surfacing by welding, one has to take into account changes of temperature caused by the application of consecutive welds (temperature increases with successive passages of the electrode as well as the cooling of already applied welds and areas previously heated), including the overlapping of melted areas (overlaps). The analytical description of the temperature field during multi-pass arc weld surfacing taking into account heat of the melted electrode material was presented by authors in the previous work [2]. 


\section{Example of computations}

Computations of a changeable in time temperature field for a surfaced plate of length $0.4 \mathrm{~m}$, width $0.2 \mathrm{~m}$ and thickness $0.05 \mathrm{~m}$ are conducted. Thermal properties of welded subject material and electrode are determined by $a=8 \cdot 10^{-6} \mathrm{~m}^{2} / \mathrm{s}$, $C_{p}=670 \mathrm{~J} / \mathrm{kg} \mathrm{K}, \rho=\rho_{e}=7800 \mathrm{~kg} / \mathrm{m}^{3}$, and $L=268 \mathrm{~kJ} / \mathrm{kg}$. Numerical simulations of the temperature field are conducted during application of five welds of length $0.2 \mathrm{~m}$ in the middle part of plate (coordinate of welds beginning $x_{0}=0.1 \mathrm{~m}$ ). Volumetric heat source with Gaussian distributed power densities are characterized by $z_{01}=0.005 \mathrm{~m}, t_{01}=4.5 \mathrm{~s}, z_{02}=0.005 \mathrm{~m}$ and $t_{02}=4.5 \mathrm{~s}$. The sum of heat powers corresponds to power obtained with welding parameters $U=24.3 \mathrm{~V}, I=232 \mathrm{~A}$, $\eta=0.6$, used in welding trials using the GMA method conducted by Klimpel et al. [3].

a)

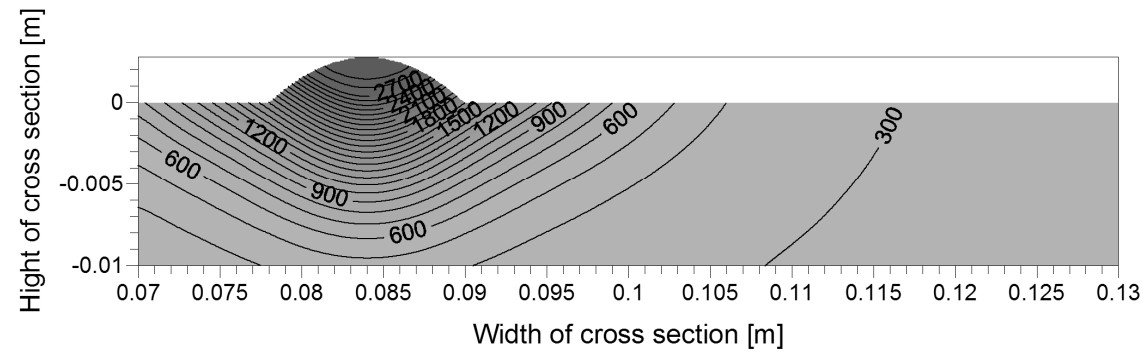

b)

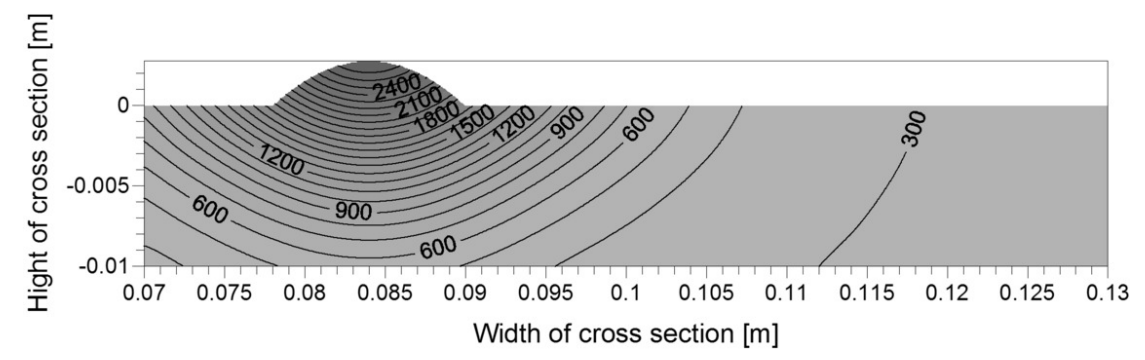

c)

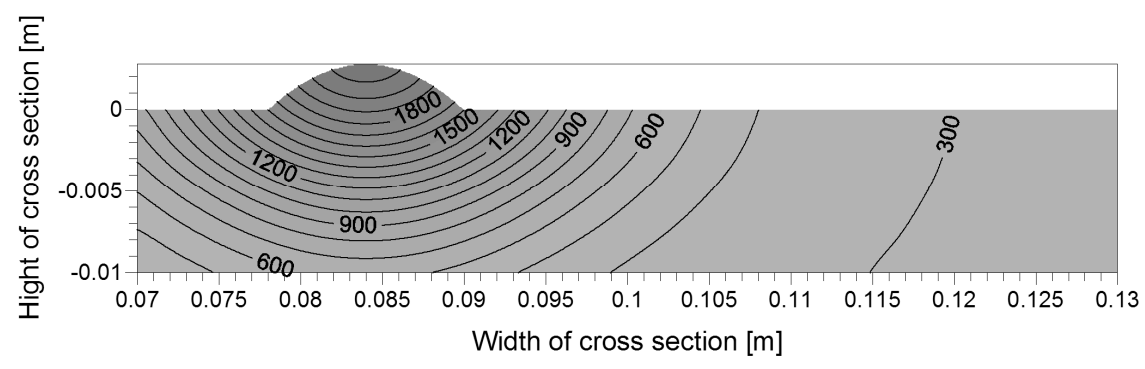

Fig. 1. Temporary temperature field in the cross-section during the application of $1 \mathrm{st}$ weld at time: a) $1 \mathrm{~s}$, b) $2 \mathrm{~s}$, c) $3 \mathrm{~s}$ after the passage of the electrode 
In the calculations are assumed: welding velocity $v=0.007 \mathrm{~m} / \mathrm{s}$, diameter of electrode wire $d=1.2 \mathrm{~mm}$, the wire speed $v_{e}=0.013 \mathrm{~m} / \mathrm{s}$, the parabolic shape of weld face [4] of height $h_{w}=2.77 \mathrm{~mm}$ and width $w_{w}=11.93 \mathrm{~mm}$, the initial temperature of the electrode $T_{e}=373 \mathrm{~K}$ (the contact temperature of wire with welding head) and the temperature $T_{L}=2773 \mathrm{~K}$. Welding overlap is obtained assuming the distance between axes of particular welds equal to $8 \mathrm{~mm}$.

In Figures 1-3 temporary temperature fields are presented in the fragment of cross-section $(x=0.2 \mathrm{~m})$ during the application of the first, second and the fifth weld. During the application of the first weld (Fig. 1), isotherms have an irregular shape symmetrical with respect to the vertical axis of weld. Subsequent passages of a heat source cause the accumulation of heat in the material and deeper heating along with the application of next welds (Figs. 2 and 3).

a)

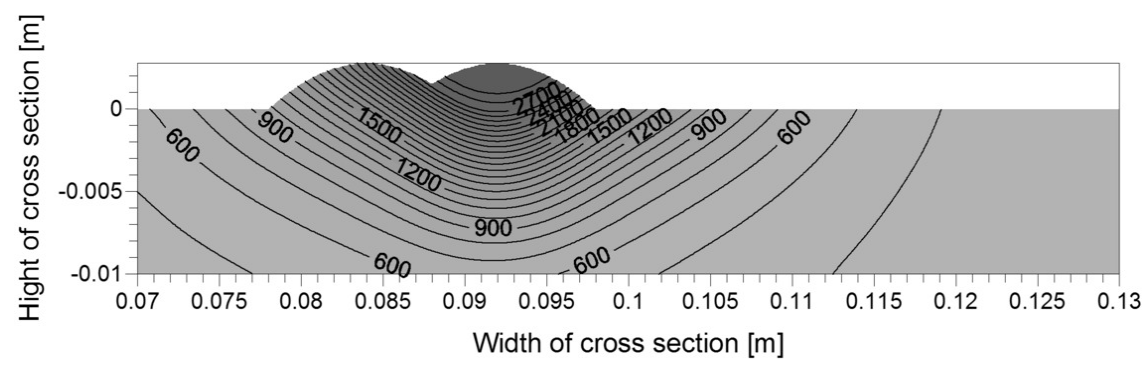

b)

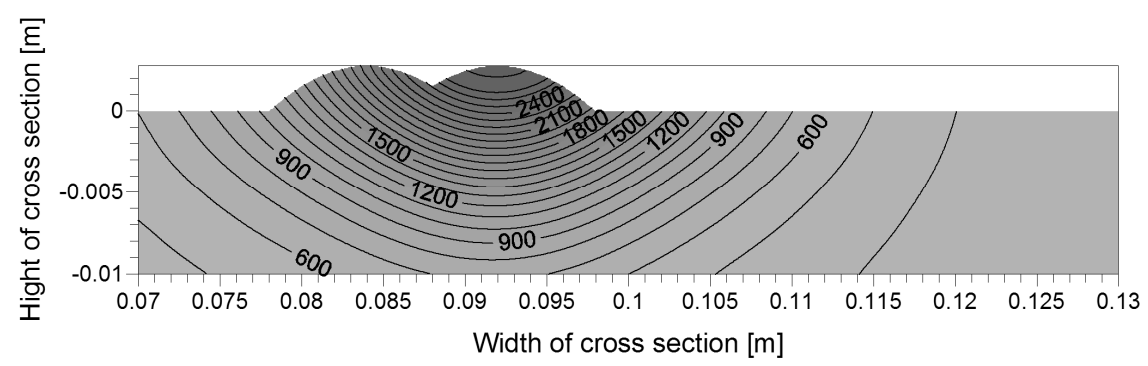

c)

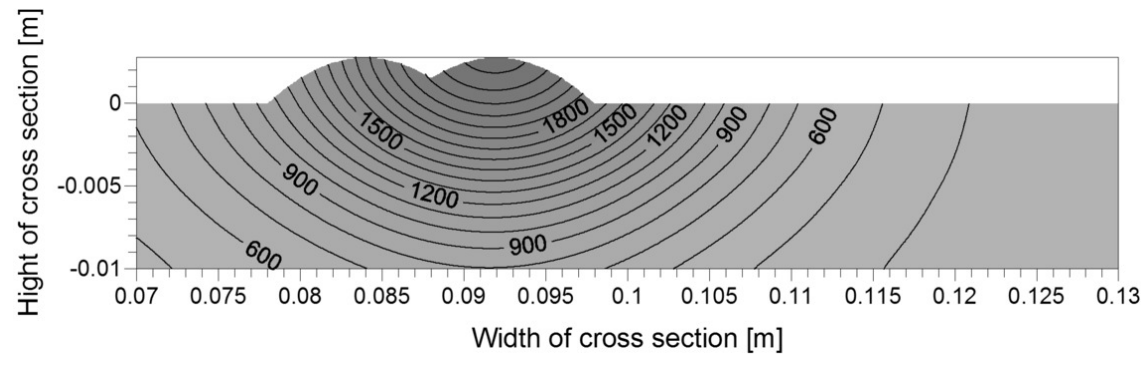

Fig. 2. Temporary temperature field in the cross-section during application of 2 nd weld at time: a) $1 \mathrm{~s}$, b) $2 \mathrm{~s}$, c) $3 \mathrm{~s}$ after the passage of electrode 
In the Figure 4 the temperature field on the surface of the welded object during the application of the first weld (for time $15 \mathrm{~s}$, electrode coordinates $x=0.2 \mathrm{~m}$, $y=0.084 \mathrm{~m}$ ) is presented.

a)

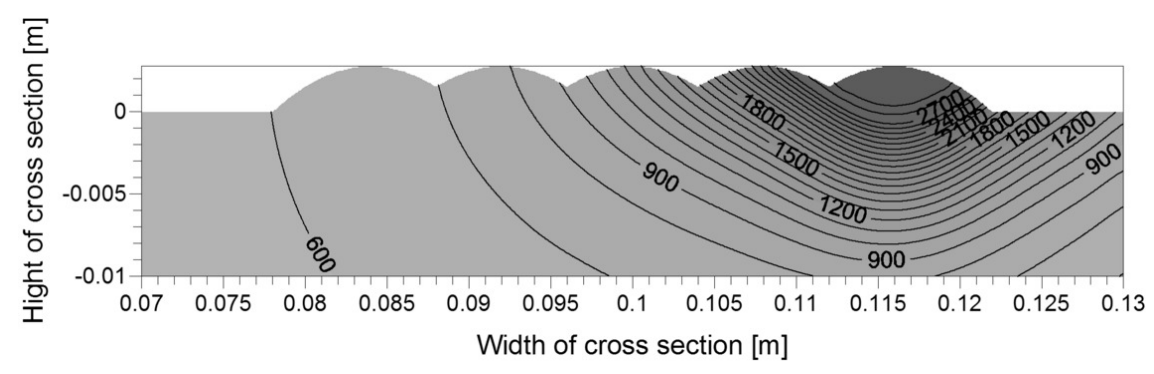

b)

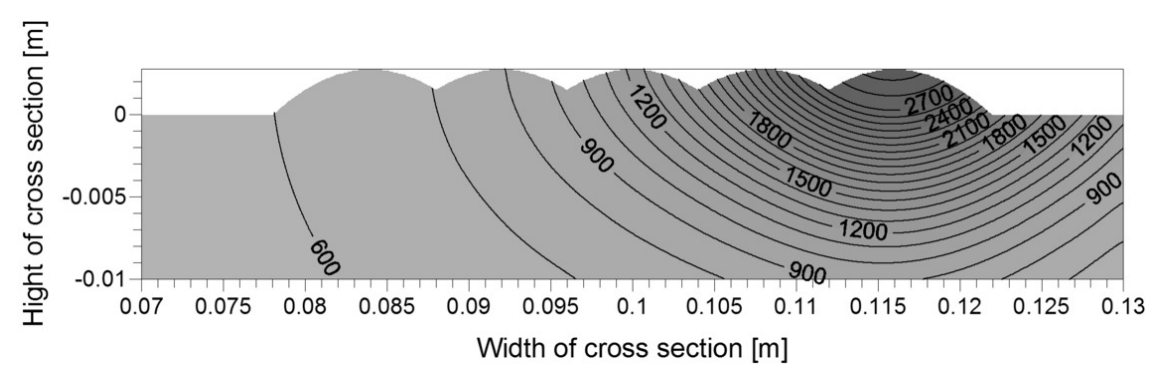

c)

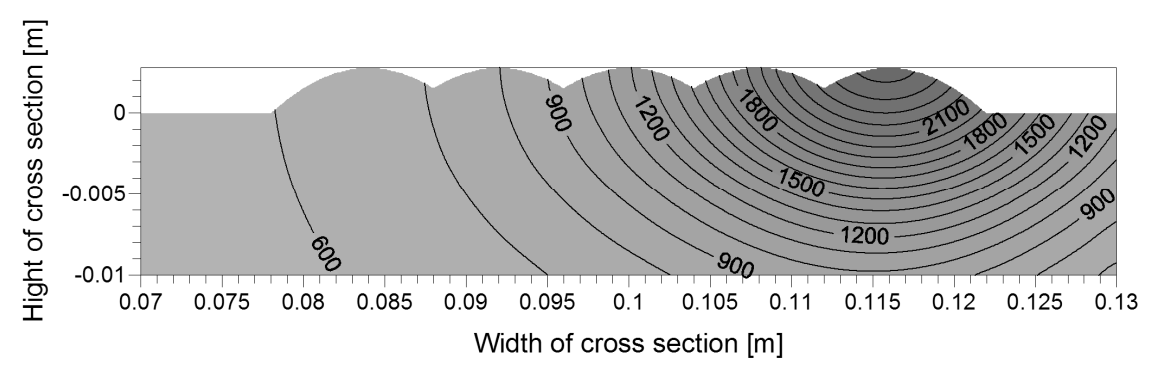

d)

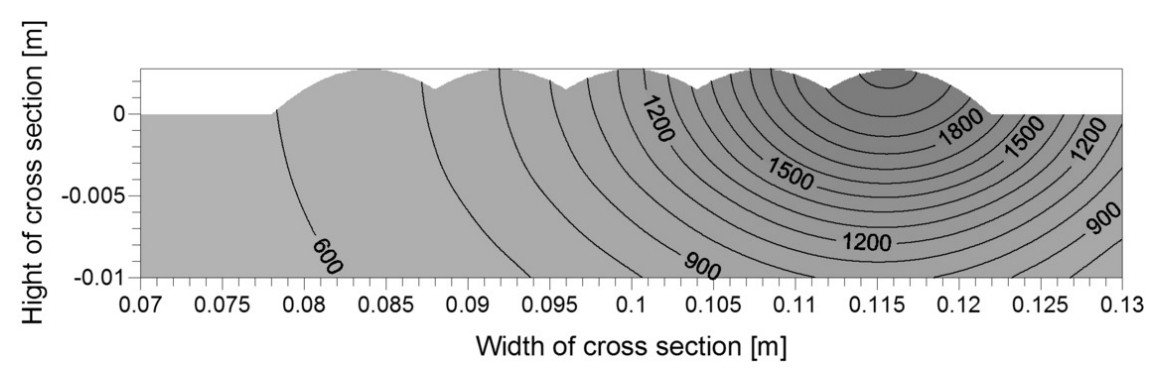

Fig. 3. Temporary temperature field in cross sections during application of 5 th weld at time: a) $1 \mathrm{~s}$, b) $2 \mathrm{~s}, \mathrm{c}) 3 \mathrm{~s}$, d) $4 \mathrm{~s}$ after the passage of electrode 


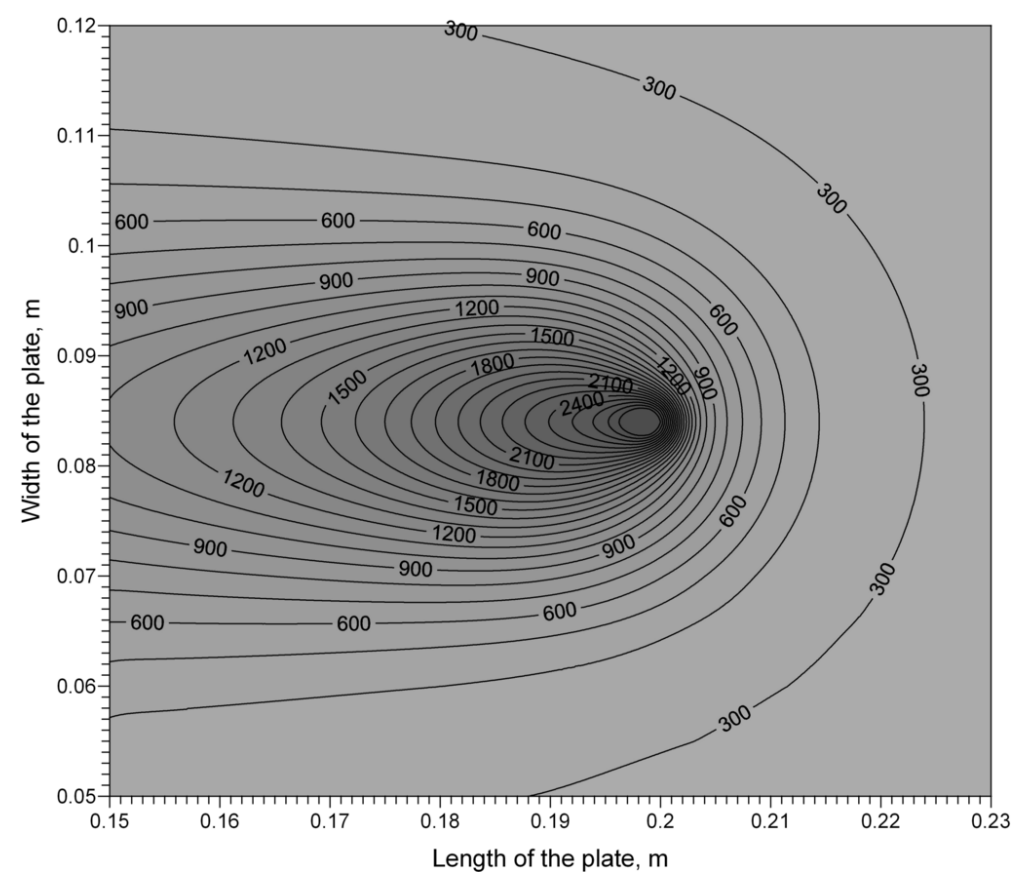

Fig. 4. Temperature distribution on the surface of element $(z=0)$ during application of 1 st weld for time $t=15 \mathrm{~s}$ (position of electrode $y=0.084 \mathrm{~m}, x=0.2 \mathrm{~m}$ )

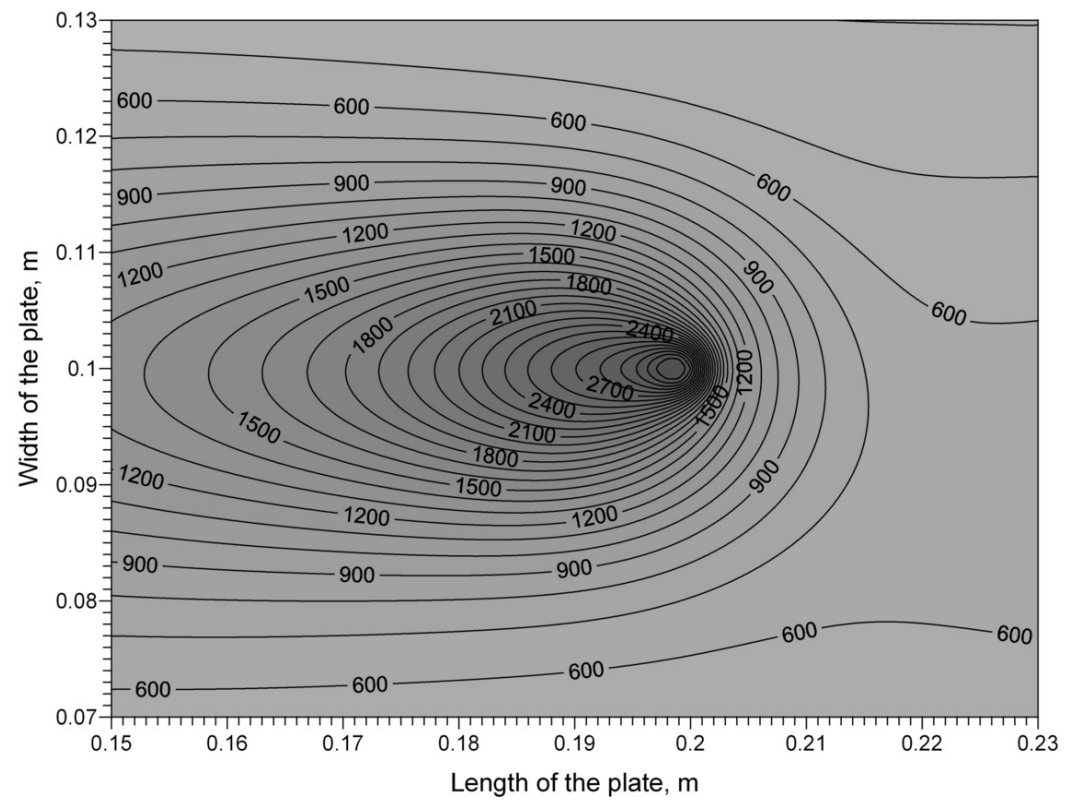

Fig. 5. Temperature distribution on the surface of element $(z=0)$ during application of $3 \mathrm{rd}$ weld for time $t=83 \mathrm{~s}$ (position of electrode $y=0.1 \mathrm{~m}, x=0.2 \mathrm{~m}$ ) 


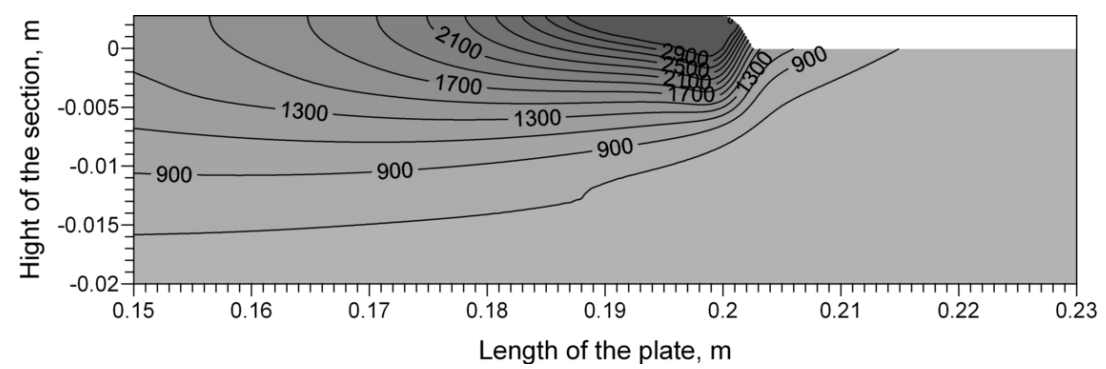

Fig. 6. Temperature field in longitudinal section in the axis of $3 \mathrm{rd}$ weld $(y=0.1 \mathrm{~m})$ during application for time $t=83 \mathrm{~s}$ (position of electrode $x=0.2 \mathrm{~m}$ )

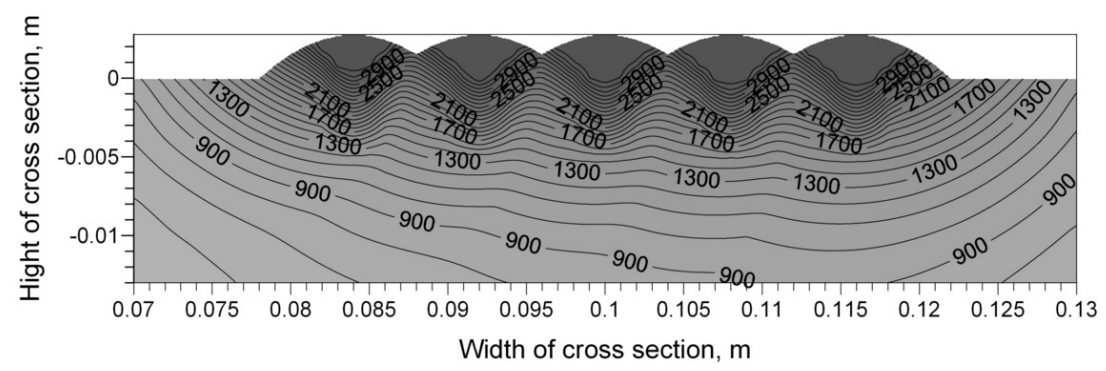

Fig. 7. Maximum temperatures in the subsequent cycles $(x=0.1)$

Temporary temperature fields during the application of the third weld (for time $t=83 \mathrm{~s}$, electrode coordinates $x=0.2 \mathrm{~m}, y=0.1 \mathrm{~m}$ ) in longitudinal sections in the axis of this weld and on the surface of surfaced element $(z=0)$ are presented in Figures 5 and 6, respectively.

Whereas maximum temperatures in the subsequent cycles in the cross-section $(x=0.1 \mathrm{~m})$ are presented in Figure 7.

Isotherms of critical temperatures allow one to determine characteristic heat affected zones (Fig. 8). Solidus temperature $1766 \mathrm{~K}$ determines fusion line, while temperatures $A_{1}=993 \mathrm{~K}$ and $A_{3}=1108 \mathrm{~K}$ determine austenitic transformation zone: partial (between $A_{l}$ and $A_{3}$ ) and full (above $A_{3}$ ). For selected points of cross section (cf. Fig. 8), whose coordinates are presented in Table 1, are determined welding thermal cycles (Fig. 9).

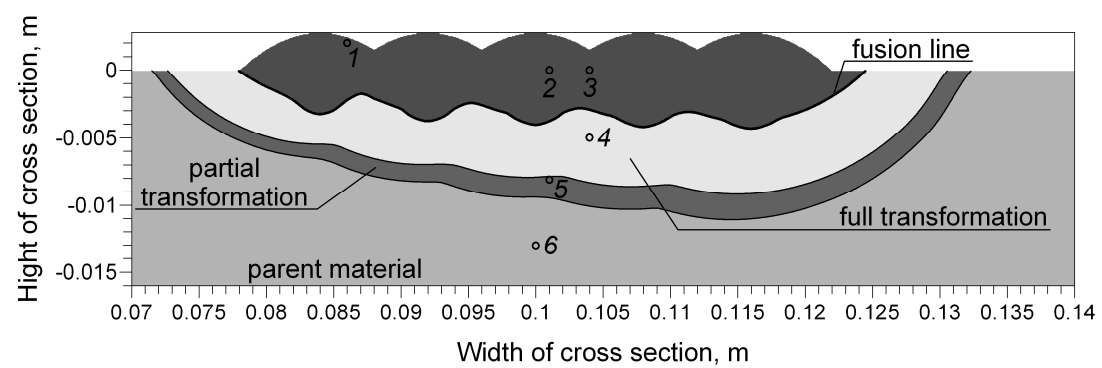

Fig. 8. Heat-affected zones in the cross-section 
1)

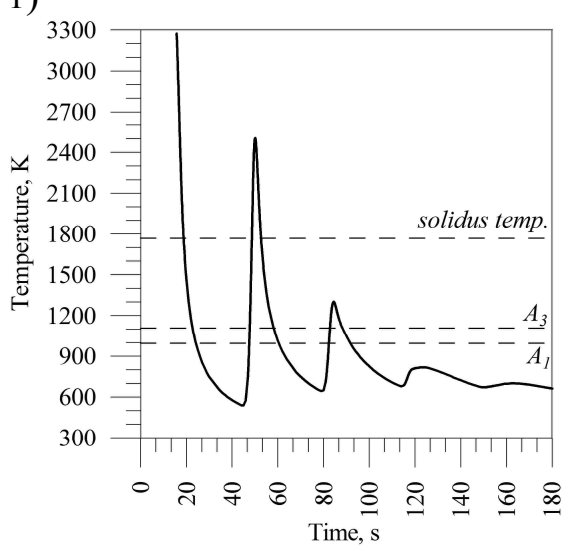

3)

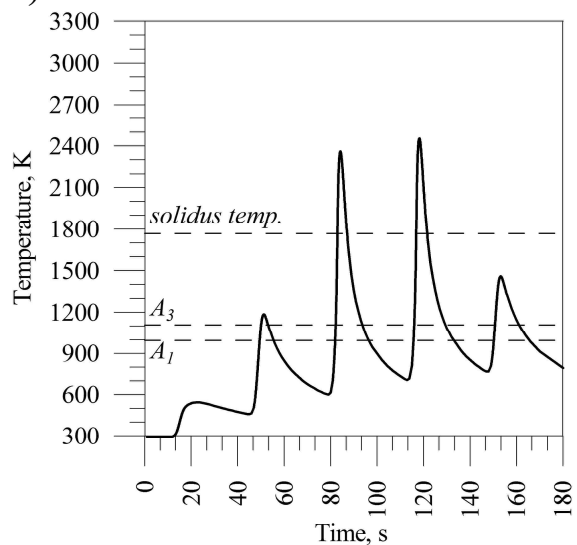

5)

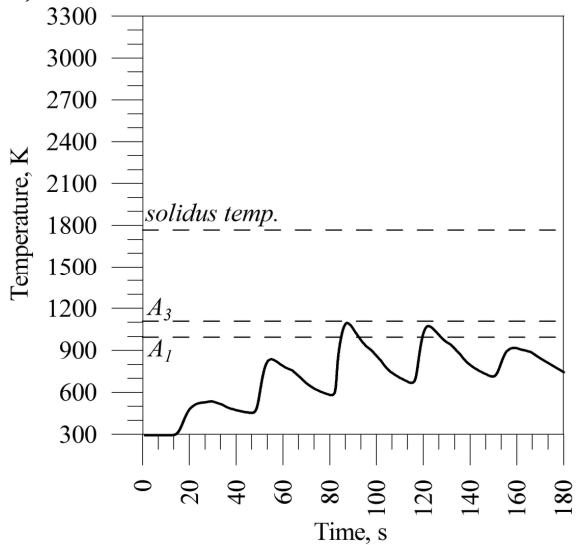

2)

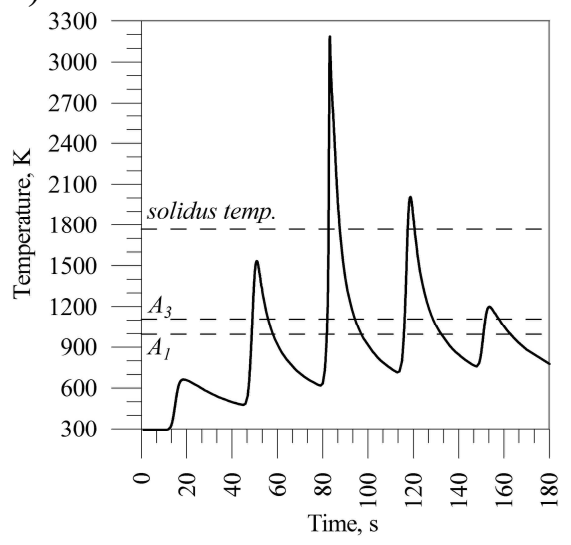

4)

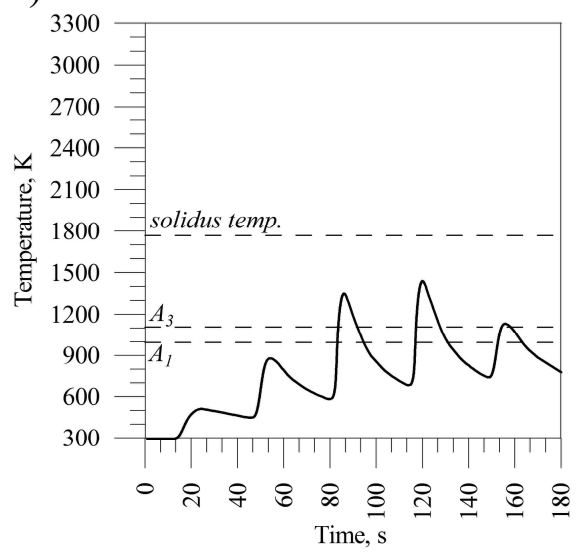

6)

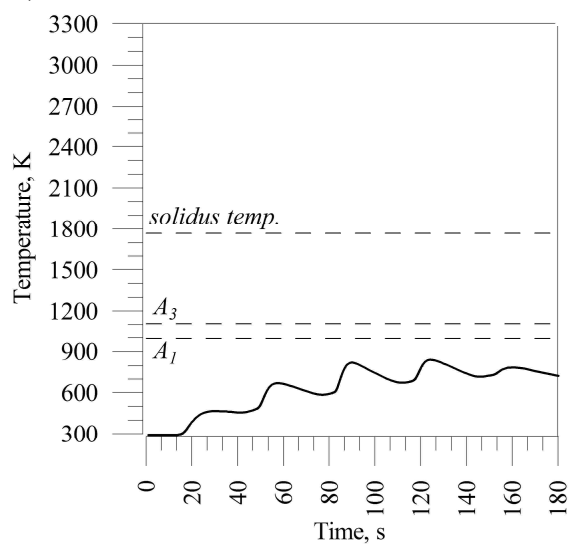

Fig. 9. Welding thermal cycles at points 1-6 
Table 1

Coordinates of selected points of cross-section

\begin{tabular}{|c|c|}
\hline No. of point & Coordinates $(y, z)[\mathrm{mm}]$ \\
\hline 1 & $86,2.775$ \\
\hline 2 & 101,0 \\
\hline 3 & 104,0 \\
\hline 4 & $104,-5$ \\
\hline 5 & $101,-8$ \\
\hline 6 & $100,-13$ \\
\hline
\end{tabular}

\section{Conclusions}

The adopted model enables determination of a temperature field, heat-affected zone (HAZ), including partial and full transformations and fusion zones, as well as analysis of thermal cycles at any point of arc weld multi-pass surfaced element. Results of numerical simulations indicate significant influence of the heat of weld on temperature distribution in fusion and full transformation zones.

\section{References}

[1] Winczek J., Temperature field in surfaced steel casts with the heat of the weld taken into account, Archiv. Foundry Eng. 2014, 14, Spec. Is. 1/2014, 121-126.

[2] Winczek J., Rygał G., Skrzypczak T., The model of temporary temperature field during multipass arc weld surfacing, Part I: Analytical description, Journal of Aplied Mathematics and Computational Mechanics 2015, 14(2), 123-130.

[3] Klimpel A., Balcer M., Klimpel A.S., Rzeźnikiewicz A., The effect of the method and parameters in the GMA surfacing with solid wires on the quality of pudding welds and the content of the base material in the overlay, Welding Int. 2006, 20, 845-850.

[4] Hrabe P., Choteborsky R., Navratilova M., Influence of welding parameters on geometry of weld deposit bead, Int. Conf. Economic Eng. Manuf. Systems, Brasov, 26-27 November 2009, Regent, 10 (2009) 3(27) 291-294. 